\title{
The influence of $v g / l 3$ genotypes on sea age at maturity is altered in farmed mowi strain Atlantic salmon
}

\author{
Fernando Ayllon ${ }^{1}$, Monica F. Solberg ${ }^{1}$, Kevin A. Glover ${ }^{1,2}$, Faezeh Mohammadi', Erik Kjærner-Semb', \\ Per Gunnar Fjelldal ${ }^{3}$, Eva Andersson ${ }^{1}$, Tom Hansen ${ }^{3}$, Rolf B. Edvardsen ${ }^{1+}$ and Anna Wargelius ${ }^{1 * \dagger}$ (D)
}

\begin{abstract}
Background: In Atlantic salmon in the wild, age at maturity is strongly influenced by the vgll3 locus. Under farming conditions, light, temperature and feeding regimes are known significantly advance or delay age at maturity. However, the potential influence of the vgl/3 locus on the maturation of salmon reared under farming conditions has been rarely investigated, especially in females.

Results: Here, we reared domesticated salmon (mowi strain) with different vgll/3 genotypes under standard farming conditions until they matured at either one, two or more than two sea winters. Interestingly, and in contrast to previous findings in the wild, we were not able to identify a link between vg/l3 and age at maturity in females when reared under farming conditions. For males however, we found that the probability of delaying maturation from one to two sea winters was significantly lower in fish homozygous for the early allele compared to homozygous fish for the late allele, while the probability for heterozygous fish was intermediate. These data also contrast to previous findings in the wild where the early allele has been reported as dominant. However, we found that the probability of males delaying maturation from two to three sea winters was regulated in the same manner as the wild.

Conclusions: Collectively, our data suggest that increased growth rates in mowi salmon, caused by high feed intake and artificial light and temperature regimes together with other possible genetic/epigenetic components, may significantly influence the impact that the vgll/3 locus has on age at maturity, especially in females.

In turn, our results show that the vgll3 locus can only to a large extent be used in selective breeding to control age at maturation in mowi males. In summary, we here show that in contrast to the situation in wild salmon, under farming conditions vgll3 does not seem to influence age at maturity in mowi females whereas in mowi males, maturing as one or two sea winters it alters the early allele effect from dominant to intermediate.
\end{abstract}

Keywords: Atlantic salmon, vgll3, Time at maturity, Age at puberty, Aquaculture, Sex dependent penetrance, Vestigial like protein 3, Genotype phenotype interaction, GxE, Reproduction

\section{Background}

Age at maturity represents an important life-history trait that is also key for sustainable Atlantic salmon (Salmo salar L.) farming. Early maturation in males causes significant negative impacts in aquaculture due to increased susceptibility to disease, hypo-osmoregulatory problems and significant production losses caused by mortality,

\footnotetext{
* Correspondence: anna.wargelius@imr.no

${ }^{+}$Rolf B. Edvardsen and Anna Wargelius are shared senior authorship

${ }^{1}$ Institute of Marine Research, P.O. Box 1870, Nordnes, NO-5817 Bergen,

Norway

Full list of author information is available at the end of the article
}

impaired growth and downgrading at harvest [1]. Moreover, early maturation may increase the risk of genetic introgression of escaped salmon into wild populations, as early maturing fish that have escaped into the wild are more likely to survive until maturation and attempt to spawn [1]. In addition, breeders may be interested in utilizing genotypes which contribute to shorter generation times. Currently, the problem with early maturation in aquaculture is controlled by artificial light regimes [2]. However, both increasing sea water temperatures associated with climate change, and a growing

(c) The Author(s). 2019 Open Access This article is distributed under the terms of the Creative Commons Attribution 4.0 International License (http://creativecommons.org/licenses/by/4.0/), which permits unrestricted use, distribution, and 
use of closed farming systems in the marine phase of production, may augment the incidence of early maturation despite the use of photoperiod control [3]. It is therefore important to explore additional options for how maturation can be controlled in salmon farming. For females, early maturation is not a production problem as very few mature as $1 \mathrm{SW}$ in farms. However, for breeders it is of great interest to reduce generation time, currently restricted by females, as this decreases the time of introduction of relevant traits to the breeding nucleus.

Recently, a genome region explaining $35-38 \%$ of the variation of sea age at maturity in wild Atlantic salmon was discovered. The genomic region found in chr25 harbors three genes, with the vestigial-like protein 3 (vgll3) gene showing the strongest signature of selection $[4,5]$. It is hypothesized that a balancing mechanism between the sexes maintains both the early and late maturation alleles within wild populations, where the allele for late maturation (L) is dominant in females while the early allele (E) is dominant in the males [5]. It should also be noted that other studies suggests a polygenic nature for sea age at maturity, therefore it is plausible that not only environmental conditions and/or vgll3 affect the trait but also other regions in the genome [6-9]. It has recently been discovered that north American Atlantic salmon populations have a low frequency of the vgll3 early allele, and instead show a linkage to grilse maturation in a region on chr21(accounting for $6 \%$ of the phenotypic variation) instead of chr25 [10]. Furthermore, in European salmon populations selection towards an increase of the vgll 3 early allele has been observed, further illustrating the importance of this genomic region in controlling age of maturation in European populations of wild salmon [11]. Also a recent study has shown a possible function of $v g l l 3$ in Granulosa and Sertoli cells of salmon ovary and testis respectively, as this protein is expressed in these cell types and regulated upon entry into maturity in both male and female salmon [12]. The differential reproductive functions of Sertoli and Granulosa cells in supporting germ cell development may further explain their differential dominance pattern in the wild.

In this study, we investigated how the vgll3 genotype influences age at maturity in domesticated males and females (commercial mowi strain) reared under standard farming conditions. Our results indicate that in females reared under normal farming conditions, vgll3 genotype is not linked with the age at maturity to the same extent as in famed males or wild females. For males however, and in contrast to previous finding in wild salmon, we found that the probability of maturing at two sea winters instead of at one sea winter was significantly higher in fish homozygous for the late allele compared to homozygous fish for the early allele, while the heterozygous genotype showed an intermediate probability. Under standard aquaculture the probability to delay maturation between two and more than two sea winter males was, like earlier findings in fish found in the wild, significantly lower in individuals homozygous for the early allele and heterozygous than in fish homozygous for the late allele.

\section{Results}

In this study we have followed 2 year-classes of fish of domesticated (commercial mowi strain) background (hereon referred to as $\mathrm{Y} 1$ and $\mathrm{Y} 2$ ) that were permitted to mature naturally under typical conditions used in commercial aquaculture. We used a binary logistic regression to estimate the predictors for the probability to delay maturation for males and females as a function of the vgll3 genotype (EE, EL and LL) and the year-class (Y1/ Y2), with factor family as random intercept.

In females, we analyzed the gene by environment interaction $(\mathrm{GxE})$ of the vgll3 alleles under standard farming conditions. A clear majority of the females in both year-classes matured as either 2SW $(n=211)$ or $>$ $2 \mathrm{SW}(n=89)$, therefore no statistical analysis was performed on the $1 \mathrm{SW}$ fish $(n=6)$. Our results indicated that the vgll3 genotype was not inked to age at maturity in salmon females in either year-class (Fig. 1a-c, Table 1), even though a substantial number of females from each genotype were assayed (Table 2), as well as a considerable number of families. In fact, most females matured as 2SW irrespective of genotype (EE-84\% $n=50$, EL-65\% $n=127$, LL-78\% $n=128$ ). The, proposed model however, predicted differences between the 2 year-classes (Fig. 1c, Table 1).

In males, EE individuals showed a significantly lower probability to delay maturation to $2 \mathrm{SW}$ compared to LL individuals. Heterozygous males showed intermediate probability to delay maturation to $2 \mathrm{SW}$, not statistically different from any type of homozygous fish (Fig. 2a-c, Table 1). The probability to delay maturation from $2 \mathrm{SW}$ to $>2 \mathrm{SW}$ was not significantly different between $\mathrm{EE}$ and EL individuals in both year classes, while the LL group was significantly different from the other two genotypes.

In both males and females reared in this study, the year-class factor had a significant effect on delaying maturation from $2 \mathrm{SW}$ to $>2 \mathrm{SW}$ (Figs. 1c, 2c, Table 1, Additional file 1). Although the fish were of the same age, Y2 fish were significantly larger than Y1 fish at smoltification, with an average weight and length in Y2 of $223.09 \mathrm{~g}+/-61.66$ and $26.08 \mathrm{~cm}+/-2.64$ in comparison to Y1: $90.29 \mathrm{~g}+/-19.92$ and $19.28 \mathrm{~cm} \mathrm{+/-}$ 1.45 (Additional file 3).

\section{Discussion}

Understanding the role of $v g l l 3$ in regulating age at maturity in Atlantic salmon reared under farming 


\section{(a) females Y1}

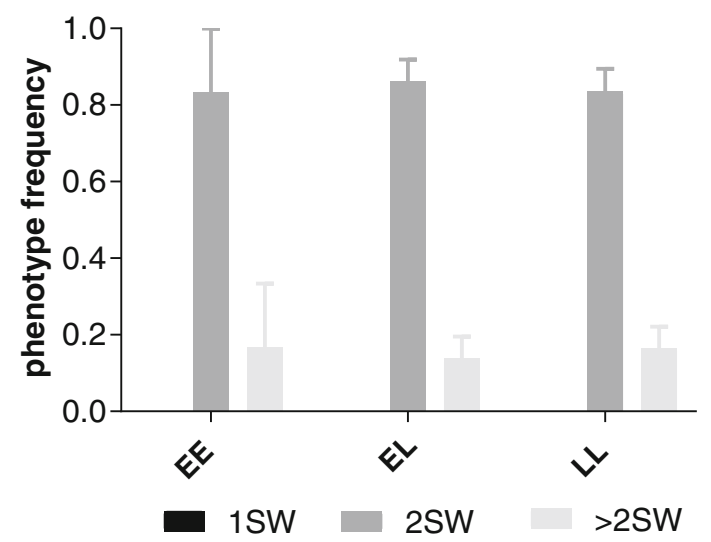

(b)

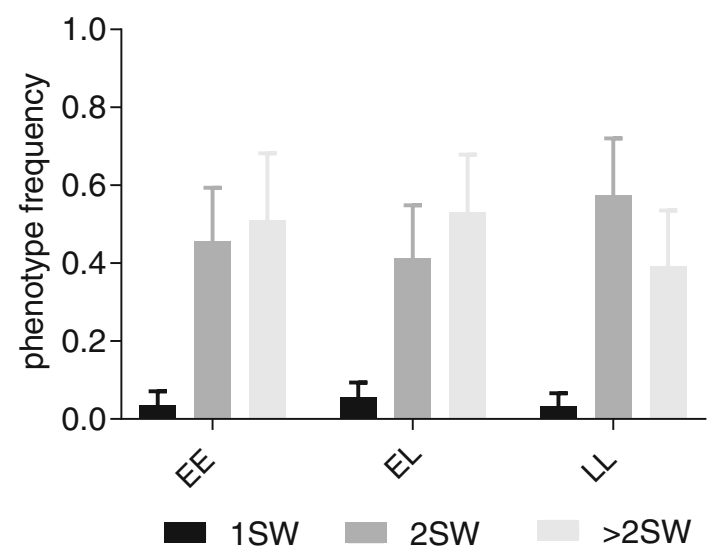

(c)

\section{Probability of delaying maturation in females}

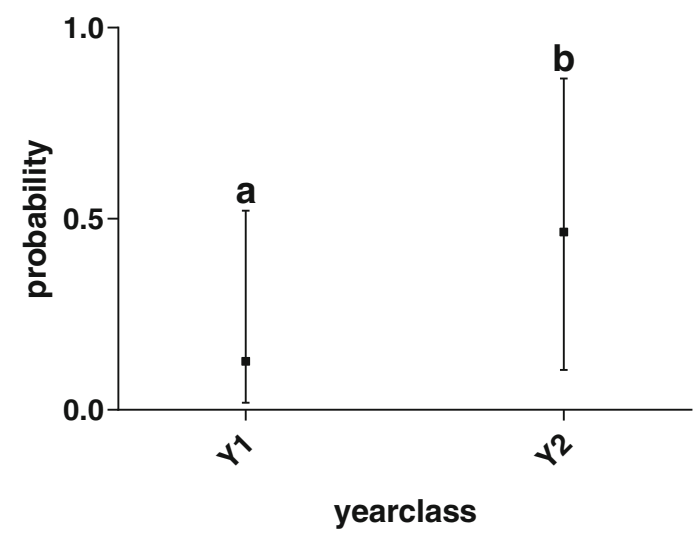

Fig. 1 Genotype phenotype interaction in females. Graphs a-b show phenotype frequencies $(1,2$ or $>2 S W$ ) per genotype (EE, EL, LL) and family in females (mowi strain) reared from two different year-classes ( $Y 1$ and $Y 2$, fig $\mathbf{a}$ and $\mathbf{b}$ respectively). Graph $\mathbf{c}$ show the probability of delaying maturation (>2SW, instead of 2SW) when comparing $\mathrm{Y} 1$ and $\mathrm{Y} 2$ females. Maturation phenotypes are denoted 1SW, 2SW and $>2 \mathrm{SW}$ and correspond to fish maturing after 1, 2 or $>2$ sea winters (SW). Genotypes are denoted as EE (Early-Early), EL (Early-Late) and LL (Late-Late). Graphs a-b shows SEM. Graph c shows confidence interval for the probability for delaying maturation, different lower-case letters indicate significant differences $(P<0.05)$

conditions is important if this gene is to be used to assist selective breeding programs with the aim of controlling maturation of salmon under farming conditions.

The undetectable association between vgll3 and female age at maturity in females documented herein, contrasts significantly with previous observations in the wild where vgll 3 significantly contributes to age at maturity [5]. It is known that salmon females are strongly affected by environmental cues such as temperature and light, and that this in turn affects time of maturity $[2,13]$. In our experiments, juvenile rearing was conducted under continuous light (6 months), the growth promoting effect of continuous light may therefore have affected GxE interaction in fresh water and possible have created an epigenetic mark [14] or affected the endocrine regulation of the brain-pituitary-gonad axis which in turn may have affected age at maturity at sea [1]. The growth spurt under continuous light is also related to a higher feed intake followed by increased growth rate [15-17]. In mice, vgll3 gene expression has been inversely related to adipogenesis and is thereby indirectly linked to metabolism and energy storage [18]. Interestingly, starvation significantly delays female maturation in Atlantic salmon [19]. Wild salmon also grow slower than domesticated fish both in the wild $[20,21]$ and under standard farming conditions [22-26], although the difference is much more profound in the latter environment. Our results therefore suggest that a higher growth rate caused by high feed intake and modulated environmental conditions (light and temperature) in mowi females, may override the genetic predisposition of the vgll3 genotype for age at maturity. However, we cannot exclude the possible influence of other genomic-regions or epigenetic effects which may contribute to the observed maturation phenotypes in farmed females and their possible interaction with the environment [5-9, 27-29]. Interestingly some North American strains have a low frequency of the vgll3 early allele and instead show linkage to grilse maturation on chr21 (6\% of the phenotypic variation) instead of chr 25, further showing that other parts of the genome can affect time of puberty in Atlantic salmon [10]. The number of families $(n=16)$ and females per family $(n=5-35$, average $\sim 18)$ in this study, may have 
Table 1 Pseudo R-square estimates. Percentage of the observed variation explained by the fixed effects (marginal) and the combined fixed and random effects (conditional)

\begin{tabular}{|c|c|c|c|c|c|c|}
\hline Maturation Delaying Probablities & Class & Family & Link & Marginal & Conditional & AIC \\
\hline Females $2 \mathrm{SW}$ to $>3 \mathrm{SW}$ & glmerMod & binomial & logit & 0.1534 & 0.3589 & 300.86 \\
\hline Males $1 \mathrm{SW}$ to $2 \mathrm{SW}$ & glmerMod & binomial & logit & 0.1386 & 0.3143 & 174.96 \\
\hline Male $2 \mathrm{SW}$ to $>2 \mathrm{SW}$ & glmerMod & binomial & logit & 0.4362 & 0.6044 & 277.09 \\
\hline
\end{tabular}

affected the ability of our model to detect weak vgll3 associations in females. Power analysis for our female model simulating 12 families with up to 15 individuals per family [30], indicated that our model may have limited power to detect genotype effects smaller than the ones detected for males in this study. However, as genotype effects get closer to male values, power to detect effects increase up to 73\% (Additional file 1). Based on this finding, our model will most likely detect genotype effects in females similar to the ones reported farmed males herein or for female salmon in the wild [5]. Therefore, vgll3 genotypes may not be useful to predict nor control the age at maturity in mowi females reared under standard farming conditions.

In males, EE individuals showed a significantly lower probability to delay maturation to $2 \mathrm{SW}$ compared to LL individuals while heterozygous males showed intermediate probability to delay maturation to $2 \mathrm{SW}$ males. Our result contrasts with earlier findings in wild salmon, where there is a lower probability to delay maturation to $2 \mathrm{SW}$ also in heterozygous fish [5]. There may be several explanations for these findings in mowi salmon males, both related to domestication genetics, epigenetics and environmental conditions during farming. The most plausible explanation is related to the environment, since it is well known that light regimes efficiently control time of maturity in salmon males under farming conditions [1]. For male salmon, several studies have also shown that prevalence of early maturing fish is lower under feed restricted regimes

Table 2 Numbers of fish for each vgll3 genotype (EE, EL and LL) and phenotype (1SW, 2SW and > 2SW) from year class 1 (Y1) and 2 (Y2)

\begin{tabular}{|c|c|c|c|c|c|c|}
\hline \multirow{2}{*}{$\begin{array}{l}\text { Phenotype/ } \\
\text { genotype }\end{array}$} & \multicolumn{3}{|l|}{$\mathrm{Y} 1$} & \multicolumn{3}{|l|}{$Y 2$} \\
\hline & $\overline{\mathrm{EE}}$ & $\mathrm{EL}$ & $\overline{\mathrm{LL}}$ & $\overline{\mathrm{EE}}$ & EL & $\mathrm{LL}$ \\
\hline \multicolumn{7}{|l|}{ Males } \\
\hline $1 S W$ & 10 & 13 & 4 & 7 & 6 & 0 \\
\hline $2 S W$ & 8 & 54 & 38 & 14 & 12 & 5 \\
\hline$>2 S W$ & 1 & 9 & 32 & 15 & 50 & 28 \\
\hline \multicolumn{7}{|c|}{ Females } \\
\hline $1 S W$ & 0 & 0 & 0 & 1 & 4 & 1 \\
\hline $2 S W$ & 13 & 53 & 80 & 14 & 30 & 21 \\
\hline$>2 S W$ & 3 & 9 & 13 & 20 & 31 & 13 \\
\hline
\end{tabular}

and in fish with lower lipid stores, clearly linking growth/ energy availability to maturity in males [31-35]. A possible genetic difference could be related to the fact that mowi salmon have been bred for both late age at maturity and fast growth for nearly 5 decades [24]. In turn, this may have affected the genetic architecture regulating age at maturity. It has been shown that other regions in the genome might contribute to age at maturity in salmon, and possible these regions in the genome are actively controlling age at maturity in the these farmed salmon [5-10, 28] . In our data, the probability to delay maturation from $2 \mathrm{SW}$ to $>2 \mathrm{SW}$ was not significantly different between EE and EL individuals in both year classes, while the LL group was significantly different from the other two genotypes. This observation is consistent with what has previously been observed in wild salmon [5].

In both mowi males and females', Y2 had a significantly higher probability of delaying maturation compared to Y1. It was observed that $\mathrm{Y} 2$ fish were significantly larger than Y1 fish at smoltification. Our results indicated that larger smolts tended to mature significantly later $(>2 \mathrm{SW}$, instead of $2 \mathrm{SW}$ ), although it is not possible to conclude whether large smolt size influenced the results due to the large number of other variables which may have caused differences in age at maturity. Nevertheless, it has previously been reported the opposite, that larger smolts are more prone to mature early [36-39]. Interestingly, the year class factor did not have a significant effect on delaying maturation in males from $1 \mathrm{SW}$ to $2 \mathrm{SW}$. The year classes were raised under different environmental conditions, e.g., deviating temperatures, that ultimately could affect freshwater phase growing rates, leading to the observed differences in the influence that smolt size and vgll3 genotype displayed age at maturity. Further studies using environmental models (temperature, light, and feed restricted or fed to ad libitum) with larger numbers of fish and families are needed to investigate if and how the outcome of the early vgll3 genotype is affected by growth rate both in fresh and seawater. If the early allele may be more prone to induce earlier maturation in males when juvenile growth rate is low, this should be further explored in production protocols for salmon.

\section{Conclusions}

In conclusion, these data indicate that the vgll3 genotype does not influence age at maturity in mowi females 


\section{(a) males Y1}

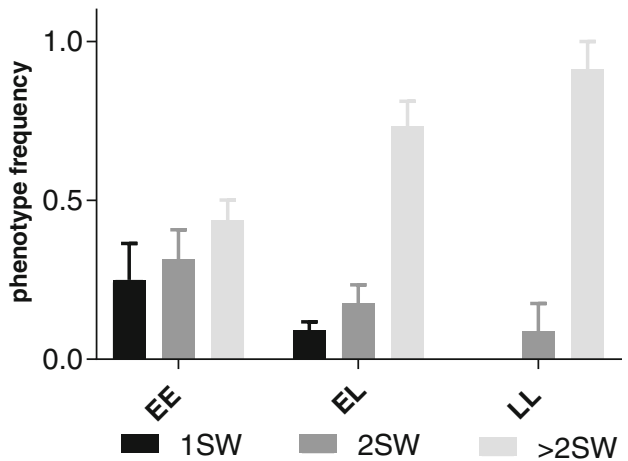

(b) males Y2

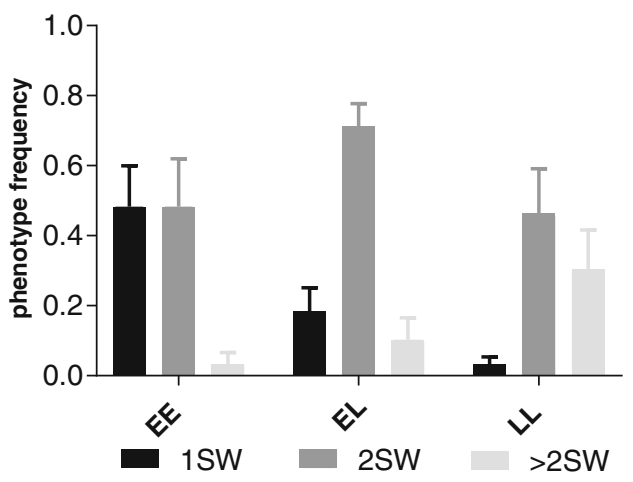

(c) Probability of delaying maturation in males

$1 S W-2 S W \quad 2 S W->2 S W$ Y1 $2 S W->2 S W$ Y2

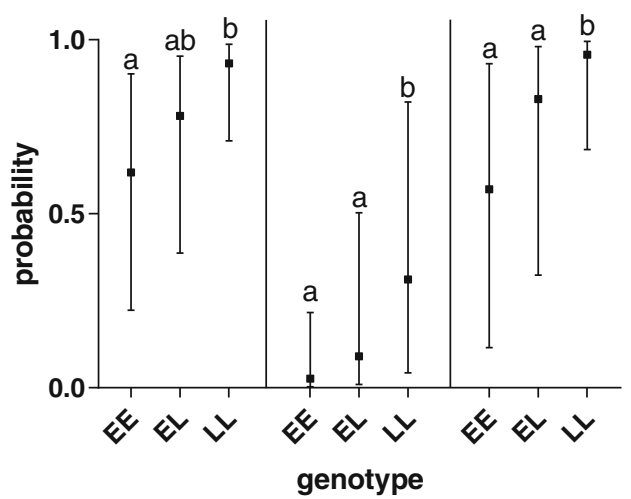

Fig. 2 Genotype phenotype interaction in males. Graphs $\mathbf{a}$ and $\mathbf{b}$ show maturity frequencies in males (mowi strain, 1, 2 or $>2 S W$ ) in relation to sea age genotypes (EE, EL and LL) and family in fish from two different year-classes (Y1 and Y2, a and $\mathbf{b}$, respectively). Graph c show the probability of delaying maturation when comparing genotypes (EE, EL and LL) and year-class (Y1 and Y2). Maturation phenotypes are denoted 1SW, 2SW and > 2SW and correspond to fish maturing after 1,2 or > 2SW sea winters (SW). Genotypes are denoted as EE (Early-Early), EL (Early-Late) and LL (Late-Late). Graphs $\mathbf{a}-\mathbf{b}$ show SEM. Graph $\mathbf{c}$ shows confidence interval for the probability for delaying maturation, different lower-case letters indicate significant differences $(P<0.05)$ 
studied herein to the same extent it does for their male counterparts. In mowi males, vgll3 genotype had a significant influence on age at maturity, although different from the wild situation. Therefore, selection for the late vgll3 allele in this domesticated strain is only likely to reduce the incidence of early maturation in males. Further research on the role of environment, genomic background, and strain specific factors may improve the understanding of these genotypes which may lead to better practice and better marker assisted selection for time of maturity in Atlantic salmon.

\section{Methods}

\section{Experiments and sampling}

The fish used in this study were all reared and sampled at the Institute of Marine Research station at Matre, western Norway. DNA from early (1SW) or late maturing farmed Atlantic salmon individuals $(\geq 2 \mathrm{SW})$ was collected to characterize the vgll3 genotype. These fish were obtained from two different year classes pedigrees (Y1 and Y2) of Mowi strain. In short, embryos from all families were plucked in equal numbers, 2010 for Y1 and 2011 for Y2. Embryos were subsequently mixed into two "common-garden" replicated tanks for both Y1 and Y2. During start-feeding in common-garden tanks, water temperature was increased to 12-14 degrees, but was dropped down to ambient temperatures approximately three weeks after first feeding had been established. Ambient temperature was not recorded during the remainder of the freshwater stage but varied between $\sim 6-14$ during the season. During the freshwater stage, fish were reared under continuous light until the late autumn prior to smoltification, upon which they were transferred over to a natural day-length to encourage smoltification as aged 1 smolts in the following spring. This is the typical regime used in commercial farming systems to prevent parr maturation [1]. In spring 2012 and 2013 respectively (Y1 and Y2), length and weight were recorded, and fin clip was sampled for DNA extraction and all fish were PIT tagged for individual identification. Upon smoltification (Aug 16th, 2012 Y1 and May 30th, 2013 Y2), the replicated fish tanks were each placed in individual $5 \times 5 \times 5 \mathrm{~m}$ sea cages and fish were here reared under ambient seawater and light conditions and checked for maturation once a year until they all reached maturation, this protocol applies to both Y1 and Y2. For details of the production and DNA parental assignment of these families see reference [26, 40]. Before transfer to sea cages, fish were sedated $(0.07$ $\mathrm{gL}^{-1}$, Finquel, ScanAqua), adipose fin clipped and PIT (passive integrated transponder) tagged. At sampling final sampling, the fish were euthanized (Finquel vet., Scanvacc AS, $0.5 \mathrm{~g} \mathrm{~L}^{-1}$ ). Fin clips were preserved on $95 \%$ ethanol, from a total of 306 males and 306 females which were used for the final analysis. Full sibling families were represented as follows: Year-class 1 (Y1) consisted of ten families from the Mowi strain, with 13, 15, 16, 5, 20, 24, 21, 5, 21 and 31 females and 33, 12, 23, 5, 8, 14, 15, 10, 32 and 17 males per family respectively. Year-class 2 (Y2) consisted of six families from the Mowi strain, in this year-class both males and females were assayed consisting of 10, 36, 12, 31, 13 and 35 males and 6, 34, 15, 27, 25 and 28 females per family respectively. Table 2 summarizes the genetic and phenotypic information of all the individuals used in this experiment ( $\mathrm{Y} 1$ and $\mathrm{Y} 2$ ).

\section{DNA extraction, genetic sex determination and genotyping}

Total DNA from selected individuals was purified from fin clips using Qiagen DNeasy Blood \& Tissue Kit (Qiagen, Hilden, Germany) according to the manufacturer's recommendations. The genetic sex of all individuals was validated by either a PCR-based methodology (as in [4]) or a DNA probe based RTPCR presence absence assay (Thermo Fisher Scientific, USA) aimed to detect the presence of the male specific $s d Y$ gene $[41,42]$.

Two different methodologies were used to determine vgll3 genotypes of all the individuals at amino acids (aa) 54 and 323. Males reared under standard farming conditions belonging to the Y1 experiment were genotyped on a Sequenom MassARRAY (Agena Bioscience, Germany) as presented in [4]. Genotypes of all fish belonging to the Y2 experiment and females from the Y1 experiment were characterized by and a custom allelic discrimination assay using qPCR (Thermo Fisher Scientific, USA) following the manufacturer's recommendations. Primers and probes used for sex-determination and genotyping are listed in Additional file 2. Genotype frequencies by sex can be found in Table 2 .

\section{Statistics}

Statistics for data arising from the fish experiment were performed in $\mathrm{R}$ version 3.4.3., using the lme4_1.1-14 and lsmeans packages for model selection and validation $[43,44]$. All fish used in the model can be found in Additional file 3. Post-hoc tests were performed using the Phia and lsmeans packages (http://CRAN.R-project.org/ package $=$ phia) [44]. To investigate effects of the vgll3 genotypes on the time at maturity binary logistic regression following a Bernoulli distribution was fitted. We tested for the effects of the three vgll3 genotypes (G), year-class $(Y)$ and the interaction between these as fixed factors. Tank $(t)$ and Family $(f)$ were included as crossed random intercept factors. The response variable, probability of delaying maturation, was coded as a binary trait with 0 and 1 values and modeled separately for males and females. Thus, to evaluate the probability of delaying maturation between 1 and 2 sea winters, one model was fitted where $1 \mathrm{SW}$ fish were coded as 0 and 2 
$\mathrm{SW}$ as 1 . Another model was fitted where the probability of delaying maturation from 2 to 3 sea winters was coded as 0 for $2 \mathrm{SW}$ fish and 1 for $>2 \mathrm{SW}$. 1SW maturation was only found in 6 females in total and was therefore excluded from the analysis.

Initial tested model is formulated as follows:

$$
\begin{aligned}
\operatorname{logit}\left(p_{i f}\right)= & \alpha+\beta_{1} x G_{i f}+\beta_{2} x Y_{i f}+\beta_{3} x G_{i f} x Y_{i f}+a_{\mathrm{t}} \\
& +b_{\mathrm{tf}}
\end{aligned}
$$

Where the probability of delaying maturation for individual $i$ belonging to family $f$ and reared in tank $\mathrm{t}$ is a function of the genotype $(G)$ and the year class $(Y)$ plus the interaction term. Model selection was performed based on the Akaike Information Criterion (AIC) where nonsignificant fixed effects were removed until no further improvement were detected [45]. No significant family variation was detected in the material. To calculate family effects confounding our results, Pseudo $R$ square calculations were performed, to illustrate the percentage of the observed variation by the random effect [46]. Briefly, marginal $R^{2}$ represents the proportion of the total variance explained by the variance in the fitted values for the fixed factors. Conditional $\mathrm{R}^{2}$ represents the proportion of variance explained by the variance in the fitted values for the fixed factors and the variance of the random effects from the total variance. For the females, only the year class factor was proven to be significant when delaying maturation from $2 \mathrm{SW}$ to $>2 \mathrm{SW}$ (Table 1, Fig. 1). Genotype was the only factor significant for males when delaying maturation from $1 \mathrm{SW}$ to $2 \mathrm{SW}$ (Table 1, Fig. 1). We performed power analysis [30] to assess the ability of our female model to detect a range of genotype effect sizes across simulated data sets, consisting of 12 families with a variable number of individuals per family ranging from 1 to 15 (Additional file 1).

\section{Additional files}

Additional file 1: Power analysis. (PDF $108 \mathrm{~kb}$ )

Additional file 2: Primer and probes used to interrogate the sex of the individuals (PCR and Presence-Absence) and the vgll3 genotypes (Sequenom and Allelic Discrimination). (PDF $48 \mathrm{~kb}$ )

Additional file 3: A table describing the individual fish number (Pit tag), smolt weight, smolt length, family, sex, sea age at maturity and $\mathrm{vg} / \mathrm{l}$ genotype. (XLSX 36 kb)

\section{Abbreviations \\ >2SW: More than two sea winters; 1SW: One sea winter; 2SW: Two sea winter; aa: Aminoacids; AIC: Akaike Information Criterion; E: Early allele; f: Family; G: Genotypes; GxE: Gene by environment interaction; L: Late allele; PIT: Passive integrated transponder; t: Tank; vgll3: Vestigial-like protein 3; Y: Yearclass; Y1: Yearclass I; Y2: Yearclass II}

\section{Acknowledgements}

We gratefully acknowledge Marine Harvest (Mowi) for donating gametes to the study. We would like to acknowledge the technical assistance of Ivar
Helge Matre and Lise Dyrhovden at the Matre facility for production of those fish.

\section{Funding}

This study was co-funded by the NRC BIOTEK2021/HAVBRUK projects; SALMAT (226221), and MATGEN (254783). NRC project INTERACT (200510) financed production of all Mowi strains used in this experiment. INTERACT (200510) funded the experiment and sampling. SALMAT (226221), and MATGEN (254783) equally funded the genotyping and hours spent for statistical analysis and writing of paper.

\section{Availability of data and materials}

All data generated or analyzed during this study are included in this published article in Additional file 3.

\section{Authors' contributions}

Conceived and designed the experiments: AW, FA, RBE, MFS, KAG. Analyzed the data: FA, MFS, FM, EK-S, PGF, TH, EA, RBE, AW. Contributed reagents/ materials/analysis tools: MFS, KAG. Wrote the paper: FA, KAG, MFS, RBE and FA, all authors read and approved the final manuscript.

\section{Ethics approval and consent to participate}

The use of these experimental animals was performed in strict accordance with the Norwegian Animal Welfare Act of 19th of June 2009, in force from 1st of January 2010. Both year classes of fish reared were approved by the Norwegian Animal Research Authority (http://www.fdu.no/fdu/), NARA, permit numbers 4268, 5296, and 5741 .

\section{Consent for publication}

Not applicable

\section{Competing interests}

The authors declare that they have no competing interests.

\section{Publisher's Note}

Springer Nature remains neutral with regard to jurisdictional claims in published maps and institutional affiliations.

\section{Author details}

${ }^{1}$ Institute of Marine Research, P.O. Box 1870, Nordnes, NO-5817 Bergen, Norway. ${ }^{2}$ Institute of Biology, University of Bergen, Bergen, Norway. ${ }^{3}$ Institute of Marine research (IMR), Matre Aquaculture Research Station, 5984 Matredal, Norway.

Received: 12 November 2018 Accepted: 25 April 2019

Published online: 06 May 2019

\section{References}

1. Taranger GL, Carrillo M, Schulz RW, Fontaine P, Zanuy S, Felip A, Weltzien FA, Dufour $\mathrm{S}$, Karlsen $\mathrm{O}$, Norberg B, et al. Control of puberty in farmed fish. Gen Comp Endocrinol. 2010;165(3):483-515.

2. Taranger GL, Haux C, Hansen T, Stefansson SO, Bjornsson BT, Walther BT, Kryvi $\mathrm{H}$. Mechanisms underlying photoperiodic effects on age at sexual maturity in Atlantic salmon, Salmo salar. Aquaculture. 1999;177(1-4):47-60

3. Good C, Davidson J. A review of factors influencing maturation of Atlantic Salmon, Salmo salar, with focus on water recirculation aquaculture system environments. J World Aquacult Soc. 2016:47(5):605-32.

4. Ayllon F, Kjaerner-Semb E, Furmanek T, Wennevik V, Solberg MF, Dahle G, Taranger GL, Glover KA, Almen MS, Rubin CJ, et al. The vgll3 locus controls age at maturity in wild and domesticated Atlantic Salmon (Salmo salar L.) males. PLoS Genet. 2015;11(11):e1005628.

5. Barson NJ, Aykanat T, Hindar K, Baranski M, Bolstad GH, Fiske P, Jacq C, Jensen AJ, Johnston SE, Karlsson S, et al. Sex-dependent dominance at a single locus maintains variation in age at maturity in salmon. Nature. 2015; 528(7582):405-8.

6. Gutierrez AP, Lubieniecki KP, Fukui S, Withler RE, Swift B, Davidson WS. Detection of quantitative trait loci (QTL) related to grilsing and late sexual maturation in Atlantic salmon (Salmo salar). Mar Biotechnol. 2014;16(1):103-10. 
7. Gutierrez AP, Yanez JM, Fukui S, Swift B, Davidson WS. Genome-wide association study (GWAS) for growth rate and age at sexual maturation in Atlantic salmon (Salmo salar). PLoS One. 2015;10(3):e0119730.

8. Johnston SE, Orell P, Pritchard VL, Kent MP, Lien S, Niemela E, Erkinaro J Primmer CR. Genome-wide SNP analysis reveals a genetic basis for sea-age variation in a wild population of Atlantic salmon (Salmo salar). Mol Ecol. 2014;23(14):3452-68.

9. Lepais O, Manicki A, Glise S, Buoro M, Bardonnet A. Genetic architecture of threshold reaction norms for male alternative reproductive tactics in Atlantic salmon (Salmo salar L.). Sci Rep. 2017;7:43552.

10. Boulding EG, Ang KP, Elliott JAK, Powell F, Schaeffer LR. Differences in genetic architecture between continents at a major locus previously associated with sea age at sexual maturity in European Atlantic salmon. Aquaculture. 2019;500:670-8.

11. Czorlich Y, Aykanat T, Erkinaro J, Orell P, Primmer CR. Rapid sex-specific evolution of age at maturity is shaped by genetic architecture in Atlantic salmon. Nat Ecol Evol. 2018;2(11):1800-7.

12. Kjaerner-Semb E, Ayllon F, Kleppe L, Sorhus E, Skaftnesmo K, Furmanek T, Segafredo FT, Thorsen A, Fjelldal PG, Hansen T, et al. Vgll3 and the hippo pathway are regulated in Sertoli cells upon entry and during puberty in Atlantic salmon testis. Sci Rep. 2018;8(1):1912.

13. Taranger GL, Haux C, Stefansson SO, Bjornsson BT, Walther BT, Hansen T. Abrupt changes in photoperiod affect age at maturity, timing of ovulation and plasma testosterone and oestradiol-17 beta profiles in Atlantic salmon, Salmo salar. Aquaculture. 1998;162(1-2):85-98.

14. Moghadam HK, Johnsen H, Robinson N, Andersen O, E HJ, Johnsen HK, Baehr VJ, Tveiten H. Impacts of early life stress on the Methylome and transcriptome of Atlantic Salmon. Sci Rep. 2017;7(1):5023.

15. Bjornsson BT, Stefansson SO, Hansen T. Photoperiod regulation of plasma growth-hormone levels during Parr-Smolt transformation of Atlantic Salmon - implications for Hypoosmoregulatory ability and growth. Gen Comp Endocrinol. 1995;100(1):73-82.

16. Nordgarden U, Fjelldal PG, Hansen T, Bjornsson BT, Wargelius A. Growth hormone and insulin-like growth factor-I act together and independently when regulating growth in vertebral and muscle tissue of Atlantic salmon postsmolts. Gen Comp Endocrinol. 2006;149(3):253-60.

17. Oppedal F, Taranger GL, Juell JE, Hansen T. Growth, osmoregulation and sexual maturation of underyearling Atlantic salmon smolt Salmo salar L. exposed to different intensities of continuous light in sea cages. Aquac Res. 1999;30(7):491-9.

18. Halperin DS, Pan C, Lusis AJ, Tontonoz P. Vestigial-like 3 is an inhibitor of adipocyte differentiation. J Lipid Res. 2013;54(2):473-81.

19. Reimers E, Kjorrefjord AG, Stavostrand SM. Compensatory growth and reduced maturation in 2nd sea winter farmed Atlantic Salmon following starvation in February and march. J Fish Biol. 1993;43(5):805-10.

20. Fleming IA, Hindar K, Mjolnerod IB, Jonsson B, Balstad T, Lamberg A Lifetime success and interactions of farm salmon invading a native population. P Roy Soc B-Biol Sci. 2000;267(1452):1517-23.

21. Skaala O, Glover KA, Barlaup BT, Svasand T, Besnier F, Hansen MM, Borgstrom R. Performance of farmed, hybrid, and wild Atlantic salmon (Salmo salar) families in a natural river environment. Can J Fish Aquat Sci. 2012;69(12):1994-2006.

22. Fleming IA, Agustsson T, Finstad B, Johnsson Jl, Bjornsson BT. Effects of domestication on growth physiology and endocrinology of Atlantic salmon (Salmo salar). Can J Fish Aquat Sci. 2002;59(8):1323-30.

23. Glover KA, Ottera H, Olsen RE, Slinde E, Taranger GL, Skaala O. A comparison of farmed, wild and hybrid Atlantic salmon (Salmo salar L.) reared under farming conditions. Aquaculture. 2009;286(3-4):203-10.

24. Glover KA, Solberg MF, McGinnity P, Hindar K, Verspoor E, Coulson MW, Hansen MM, Araki H, Skaala $\varnothing$, Svåsand T. Half a century of genetic interaction between farmed and wild Atlantic salmon: status of knowledge and unanswered questions. Fish Fish. 2017;1(39):1-38.

25. Solberg MF, Skaala O, Nilsen F, Glover KA. Does domestication cause changes in growth reaction norms? A study of farmed, wild and hybrid Atlantic salmon families exposed to environmental stress. PLoS One. 2013; 8(1):e54469.

26. Solberg MF, Zhang ZW, Nilsen F, Glover KA. Growth reaction norms of domesticated, wild and hybrid Atlantic salmon families in response to differing social and physical environments. BMC Evol Biol. 2013;13:234.

27. Andersen O, Xu C, Timmerhaus G, Kirste KH, Naeve I, Mommens M, Tveiten $H$. Resolving the complexity of vitellogenins and their receptors in the tetraploid Atlantic salmon (Salmo salar): ancient origin of the phosvitin-less VtgC in chondrichthyean fishes. Mol Reprod Dev. 2017;84(11):1191-202.

28. Christensen KA, Gutierrez AP, Lubieniecki KP, Davidson WS. TEAD3, implicated by association to grilsing in Atlantic salmon. Aquaculture. 2017; 479:571-8.

29. Kusche H, Cote G, Hernandez C, Normandeau E, Boivin-Delisle D, Bernatchez L. Characterization of natural variation in north American Atlantic Salmon populations (Salmonidae: Salmo salar) at a locus with a major effect on sea age. Ecol Evol. 2017;7(15):5797-807.

30. Green P, MacLeod CJ. SIMR: an R package for power analysis of generalized linear mixed models by simulation. Methods Ecol Evol. 2016;7(4):493-8.

31. Rowe DK, Thorpe JE, Shanks AM. Role of fat Stores in the Maturation of male Atlantic Salmon (Salmo-Salar) Parr. Can J Fish Aquat Sci. 1991;48(3): 405-13.

32. Shearer KD, Silverstein JT, Plisetskaya EM. Role of adiposity in food intake control of juvenile Chinook salmon (Oncorhynchus tshawytscha) (vol 118, pg 1209, 1997). Comp Biochem Physiol A Mol Integr Physiol. 1998;119(3): 869-70.

33. Shearer KD, Swanson P. The effect of whole body lipid on early sexual maturation of 1+age male Chinook salmon (Oncorhynchus tshawytscha). Aquaculture. 2000;190(3-4):343-67.

34. Silverstein JT, Shearer KD, Dickhoff WW, Plisetskaya EM. Effects of growth and fatness on sexual development of Chinook salmon (Oncorhynchus tshawytscha) parr. Can J Fish Aquat Sci. 1998;55(11):2376-82.

35. Vikingstad E, Andersson E, Hansen TJ, Norberg B, Mayer I, Stefansson SO, Fjelldal PG, Taranger GL. Effects of temperature on the final stages of sexual maturation in Atlantic salmon (Salmo salar L.). Fish Physiol Biochem. 2016; 42(3):895-907.

36. Fjelldal PG, Schulz R, Nilsen TO, Andersson E, Norberg B, Hansen TJ. Sexual maturation and smoltification in domesticated Atlantic salmon (Salmo salar L.) - is there a developmental conflict? Phys Rep. 2018;6(17):e13809.

37. Hutchings JA, Jones MEB. Life history variation and growth rate thresholds for maturity in Atlantic salmon, Salmo salar. Can J Fish Aquat Sci. 1998;55: 22-47.

38. Nicieza AG, Brana F. Relationships among smolt size, marine growth, and sea age at maturity of Atlantic Salmon (Salmo-Salar) in northern Spain. Can J Fish Aquat Sci. 1993;50(8):1632-40.

39. Salminen M. Relationships between smolt size, postsmolt growth and sea age at maturity in Atlantic salmon ranched in the Baltic Sea. J Appl Ichthyol. 1997;13(3):121-30.

40. Solberg MF, Fjelldal PG, Nilsen F, Glover KA. Hatching time and alevin growth prior to the onset of exogenous feeding in farmed, wild and hybrid Norwegian Atlantic Salmon. PLoS One. 2014;9(12):e113697.

41. Eisbrenner WD, Botwright N, Cook M, Davidson EA, Dominik S, Elliott NG, Henshall J, Jones SL, Kube PD, Lubieniecki KP, et al. Evidence for multiple sex-determining loci in Tasmanian Atlantic salmon (Salmo salar). Heredity (Edinb). 2014;113(1):86-92.

42. Yano A, Nicol B, Jouanno E, Quillet E, Fostier A, Guyomard R, Guiguen Y. The sexually dimorphic on the $Y$-chromosome gene ( $(\mathrm{d}) \mathrm{Y}$ ) is a conserved male-specific Y-chromosome sequence in many salmonids. Evol Appl. 2013; 6(3):486-96.

43. Bates D, Maechler M, Bolker B, Walker S. Ime4: linear mixed-effects models using Eigen and S4. R package version 1.1-6; 2014.

44. Lenth RV. Least-squares means: the R package Ismeans. J Stat Softw. 2016; 69(1):1-33.

45. Zuur AF, leno EN, Walker NJ, Saveliev AA, Smith GM. Mixed effects models and extensions in ecology with R. New York: Springer-Verlag; 2009.

46. Nakagawa S, Schielzeth $H$. A general and simple method for obtaining R2 from generalized linear mixed-effects models. Methods Ecol Evol. 2013;4(2): 133-42. 